\title{
Application of PI and MPPT Controller to DC-DC Converter for Constant Voltage \& Power Application
}

\author{
Nibedita Swain ${ }^{1}$, Dr. C.K. Panigrahi ${ }^{2}$, Dr. S.M. Ali ${ }^{3}$ \\ ${ }^{1}$ PhD Scholar, KIIT University \\ ${ }^{2,3}$ Prof., KIIT University
}

\begin{abstract}
This article presents simulation of perturb and observe maximum power point tracking (MPPT) algorithm used in solar PV systems with direct control method. The main difference of the proposed system to existing MPPT systems includes addition of PI control loop along with MPPT control circuit and investigation of the effect of adding to control circuit. The resultant system is capable of tracking MPPs accurately with change in irradiation level rapidly without steady-state oscillation, and also, its dynamic performance is satisfactory. MATLAB and SIMULINK software were employed for simulation studies.
\end{abstract}

\section{Introduction}

Renewable energy systems are growing very fast in all over the world and the research in PV and wind motivate the researchers to think about new control mechanisms to implement for some useful task. This article mainly focuses on MPPT based PV system. PV modules have nonlinear characteristics which are determined by solar insolation and temperature that affects the overall output power of the system. To account for this nonlinearity, maximum power point tracking (MPPT) technique is implemented to increase the efficiency of the photovoltaic system. A CUK Converter is fed from PV source with different electrical characteristics for transferring power to a load. In this paper, a PI controller is designed for the CUK converter to extract the maximum power from the PV source keeping constant output voltage for a particular load. The Perturb and observe (P\&O) algorithm along with PI controller improves the overall performance of the converter system. One of the energy sources which are profusely available on earth is solar energy. The unavailability of grid power in rural area makes solar energy a better alternative. So a standalone PV system can be utilized there. Solar photo voltaic system can be connected to grid also for utilising the PV power. Solar panel efficiency depends on the solar cell materials and the control mechanism used. Maximum Power Point Tracking (MPPT) algorithm which is a new control mechanism is used for extracting maximum power from PV array irrespective of environmental conditions. This results in increased efficiency of solar modules. CUK converter is placed in between load and PV source. The proposed model for this for this converter is given in Fig: 1.

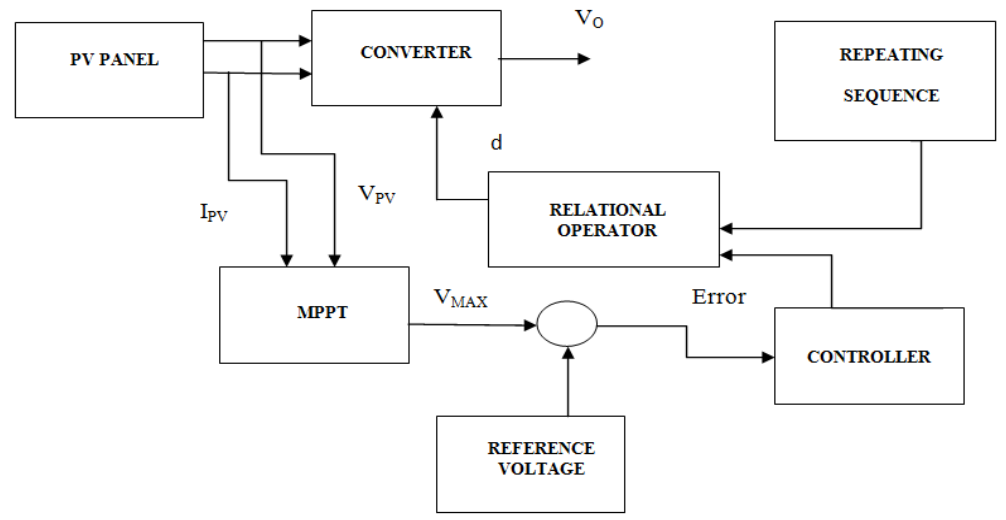

Fig: 1 Schematic representation of proposed system

\section{Design of PV Module And MPPT}

PV module consists of number of solar cells which are connected in series or parallel. It converts sunlight directly to dc power. PV panel works under the phenomenon of photoelectric effect. When solar cell is exposed to sunlight, it converts solar energy directly into electrical energy. Here the PV module consists of 44 solar cells in series each having open circuit voltage of 0.6 volt and short circuit current of 4.75 ampere. This array develops the power from the solar energy directly and it will be changing depending upon the temperature and solar irradiances. Fig: 2 show the equivalent circuit diagram of a solar cell. 


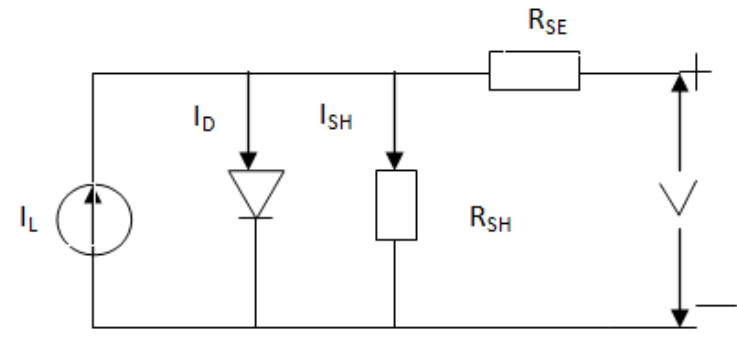

Fig: 2 Equivalent circuit diagrams for a solar cell

\section{A.MPPT Technique}

Photovoltaic systems generally use a maximum power point tracking (MPPT) technique to extract maximum possible power from the PV module irrespective of the perturbation in insolation and temperature. PV modules have relatively very low conversion efficiency; therefore it requires MPPT technique for controlling the solar array power. The Maximum Power Point Tracking (MPPT) is a technique by means of which maximum power can be extracted from the Photovoltaic (PV) Systems. To improve the energy efficiency, it is relevant to operate the total PV module always at its maximum power point. Many maximum power point Tracking (MPPT) techniques are available in the present era and among all these techniques $\mathrm{P} \& \mathrm{O}$ and incremental conductance algorithms are generally used in PV system for obtaining maximum power point. In this paper $\mathrm{P} \& \mathrm{O}$ MPPT technique is described in which it involves the perturbation in terminal voltage.

There are various methods used for maximum power point tracking. Few are listed below:

$>$ Perturb and Observe method $(\mathrm{P} \& \mathrm{O})$

$>$ Hill climbing $(\mathrm{HC})$ method

$>$ Incremental Conductance (IC) method

$>$ Constant Voltage $(\mathrm{CV})$ method

$>$ Constant Current $(\mathrm{CC})$ method

$>$ Fuzzy logic control(FLC)

Perturb and Observe method

In this method the power of the module changes due to slight perturbation. If the power increases due to the perturbation then the perturbation is continued in that direction. After the peak power is reached the power at the next instant decreases and hence after that the perturbation reverses. The algorithm is developed for setting a reference voltage of the module corresponding to the peak voltage of the module. A PI controller then acts moving the operating point of the module to that particular voltage level. This algorithm is very simple and easy to implement. Among described all MPPT methods $\mathrm{P} \& \mathrm{O}$ method is used here for maximum power point tracking . The flow chart for this method is shown in fig: 3 .

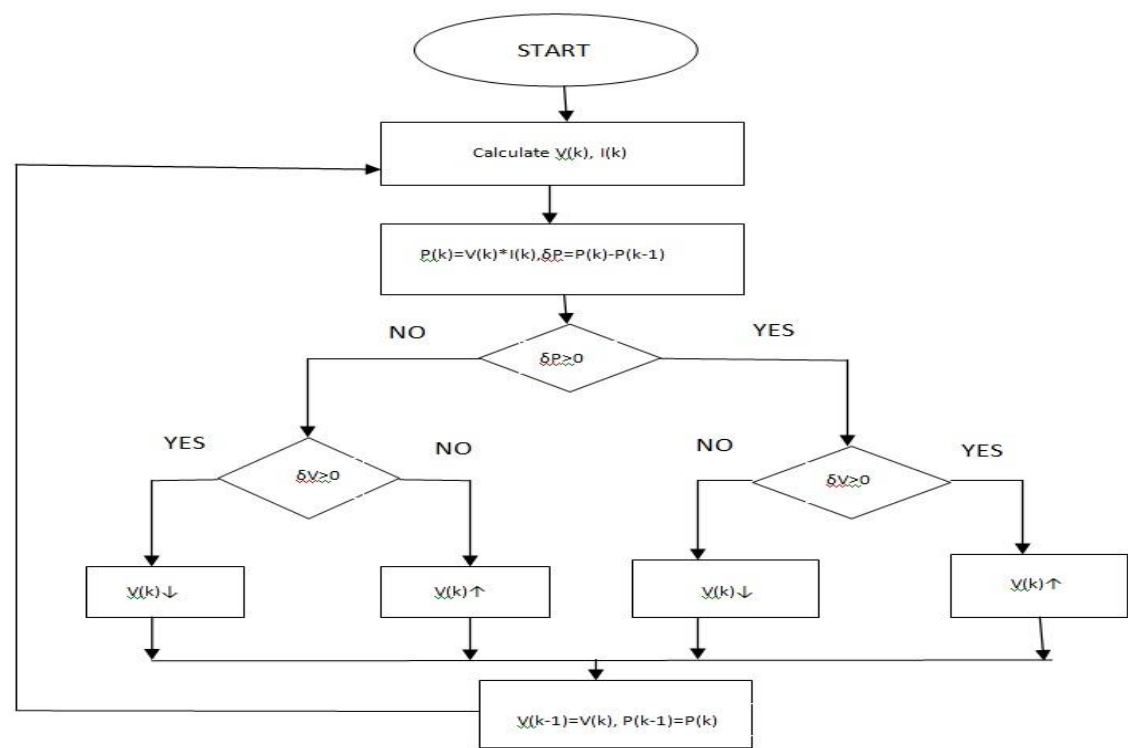

Fig.:3 Flow chart of Perturb and Observe method 
The main aim of this controller is to regulate the operating point of the system when the environment conditions vary. The dc-dc converter along with the solar-PV array regulates the operating point through a MPPT controller. Here perturb and observe $(\mathrm{P \& O})$ method is used as a MPP tracking. The algorithm is programmed in MATLAB embedded function and PI controller is designed for regulating the voltage at the output side. From the characteristic curve it is observed that the maximum power will be increased and the system efficiency will be decreased by increasing the irradiance level.

In this paper two control mechanisms are used, one is MPPT controller another one is PI controller. The MPPT controller is used for maximum power point tracking irrespective of the variation in irradiance and temperature and the output of the MPPT controller is the reference voltage which is compared with the converter output voltage. The error goes to the PI controller and the output of the PI controller is compared with the repeating sequence for generating gate pulse which goes to the switch. The use of PI controller makes the output voltage constant.

\section{Selection Of Proper Converter}

Switch mode power supplies are the replacement of the linear regulators due to certain factors such as high efficiency, light weight, smaller size and low switching losses. Buck-boost converter and CUK converter are often used for this operation because both buck operation and boost operation for the output voltage can be achieved. Although the buck-boost configuration is cheaper than the CUK converter but the disadvantages are discontinuous input current, high peak currents in power components, and poor transient response, make it less efficient. The CUK converter also provides better output voltage due to the presence of inductor at the output side. Fig: 4 show the circuit configuration of CUK converter.

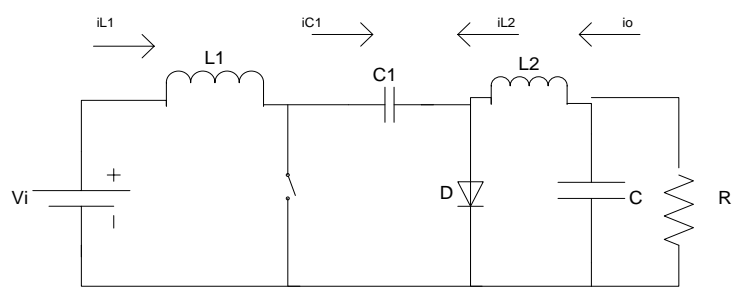

Fig: 4 circuit configuration of CUK converter

In this converter the output voltage is opposite to the input voltage. Here the non-isolated CUK converter is described in continuous conduction mode. The converter has two modes of operation such as switch on and switch off mode. The dynamic analysis is based upon the voltage equations and current equations of inductor and capacitor respectively .Fig:5 shows the on state of the CUK converter when the switch is on.

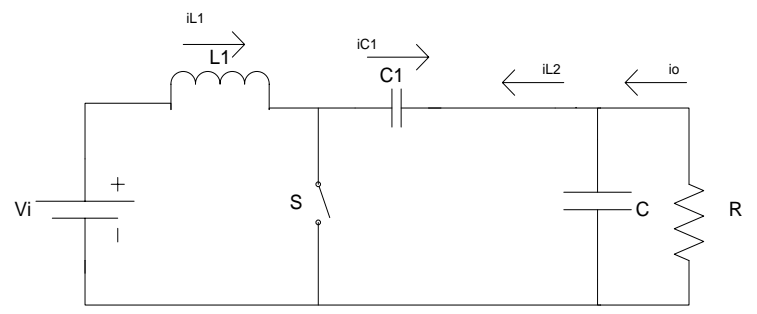

Fig: 5 CUK Converter during ON state

When the switch ' $\mathrm{S}$ ' is on, current flowing in both the inductances increase, at the same time the voltage through capacitance $\mathrm{C}_{1}$ reverse biases diode $\mathrm{D}$ and turns it off. When the switch ' $\mathrm{S}$ ' is OFF, at the same time the input voltage is turned on and the diode $\mathrm{D}$ is forward biased and capacitance $\mathrm{C}_{1}$ is charged through $\mathrm{L}_{1}$, $\mathrm{D}$ and the input supply $\mathrm{V}_{\mathrm{i}}$. Fig: 6 shows the off state circuit configuration of CUK converter.

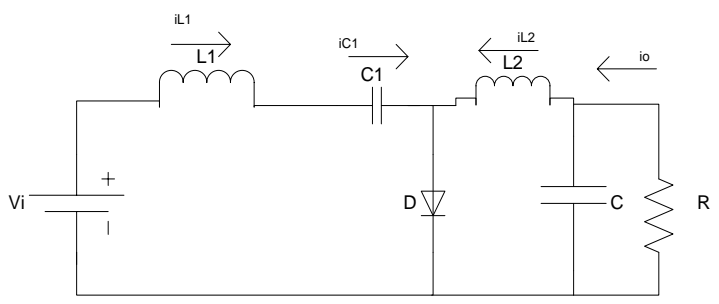

Fig: 6 CUK Converter during OFF state 
The converter is operating in boost mode for PV application. The relationship between output and input currents and voltages are given in equation (1) and (2) respectively.

$$
\begin{aligned}
& \frac{V_{o}}{V_{\text {in }}}=\frac{D}{(1-D)} \\
& \frac{I_{o}}{I_{\text {in }}}=\frac{D}{(1-D)}
\end{aligned}
$$

The voltage ratio and current ratio are same as buck boost converter. The only difference is the input and output currents are continuous and ripple free.

The specification for the CUK converter used in simulation was selected as follows:

$\checkmark \quad$ Input voltage $=25$ volt

$\checkmark$ Source side inductance $\mathrm{L}_{1}=1 \mathrm{mH}$

$\checkmark$ Duty ratio $=80 \%$

$\checkmark \quad$ Source side Capacitance $\mathrm{C}_{1}$ (PV side $)=100 \mathrm{uF}$

$\checkmark \quad$ Filter inductance $\mathrm{L}_{2}=1 \mathrm{mH}$

$\checkmark$ Capacitor $\mathrm{C}_{2}$ (filter capacitor at output side $)=450 \mathrm{uF}$

$\checkmark \quad$ Resistive load $=130 \mathrm{ohm}$

$\checkmark \quad$ Switching frequency $=5 \mathrm{kHz}$

\section{Transfer Function Model of CUK Converter}

The state space model for ON state mode and OFF state mode are given in equation (3) and (4) respectively which can be obtained from differential equation model and the output voltage remains same for both the states and given in (5)

$$
\left[\begin{array}{c}
\dot{i_{L 1}} \\
i_{L 2} \\
\dot{v_{C 1}} \\
v_{C 2}
\end{array}\right]=\left[\begin{array}{cccc}
0 & 0 & 0 & 0 \\
0 & 0 & \frac{1}{L_{2}} & -\frac{1}{L_{2}} \\
0 & -\frac{1}{C_{1}} & 0 & 0 \\
0 & \frac{1}{C_{2}} & 0 & -\frac{1}{R C_{2}}
\end{array}\right]\left[\begin{array}{c}
i_{L 1} \\
i_{L 2} \\
v_{C 1} \\
v_{C 2}
\end{array}\right]+\left[\begin{array}{c}
\frac{1}{L_{1}} \\
0 \\
0 \\
0
\end{array}\right] V_{i} \ldots \ldots \ldots(3)
$$

$\left[\begin{array}{c}i_{L 1} \\ i_{L 2} \\ \dot{v_{C 1}} \\ \dot{v_{C 2}}\end{array}\right]=\left[\begin{array}{cccc}0 & 0 & -\frac{1}{L_{1}} & 0 \\ 0 & 0 & 0 & -\frac{1}{L_{2}} \\ \frac{1}{C_{1}} & 0 & 0 & 0 \\ 0 & \frac{1}{C_{2}} & 0 & -\frac{1}{R C_{2}}\end{array}\right]\left[\begin{array}{c}i_{L 1} \\ i_{L 2} \\ v_{C 1} \\ v_{C 2}\end{array}\right]+\left[\begin{array}{c}\frac{1}{L_{1}} \\ 0 \\ 0 \\ 0\end{array}\right] V_{i} \ldots \ldots \ldots(4)$

$v_{0}=\left[\begin{array}{llll}0 & 0 & 0 & 1\end{array}\right]\left[\begin{array}{c}i_{L 1} \\ i_{L 2} \\ v_{C 1} \\ v_{C 2}\end{array}\right] \ldots \ldots \ldots .(5)$

Using state space averaging technique as given in equation (6) and (7)

$$
\begin{aligned}
& \dot{x}=\left[A_{1} d+A_{2}(1-d)\right] x+\left[B_{1} d+B_{2}(1-d)\right] v_{i} \\
& v_{o}=\left[C_{1} d+C_{2}(1-d)\right] x \ldots \ldots \ldots(7)
\end{aligned}
$$

The transfer function model with respect to input and duty ratio is obtained as in (8) and (9) 


$$
\begin{aligned}
& \frac{v_{o}(s)}{v_{i n}(s)}=C(S I-A)^{-1} B+D \ldots \ldots \ldots(8) \\
& \frac{v_{0}(s)}{d(s)}=C[S I-A]^{-1}\left[\left(A_{1}-A_{2}\right) x+\left(B_{1}-B_{2}\right) v_{i n}\right]+\left(C_{1}-C_{2}\right) x
\end{aligned}
$$

Where

$$
\begin{aligned}
& A=A_{1} \times d+A_{2} \times(1-d) \\
& B=B_{1} \times d+B_{2} \times(1-d) \\
& C=C_{1} \times d+C_{2} \times(1-d)
\end{aligned}
$$

$A_{1}, A_{2}$ are the on state and off state matrix, $B_{1}$ and $B_{2}$ are the on state and off state input matrix and $C_{1}$ and $C_{2}$ are the on state and off state output matrix respectively.

The transfer function with respect to duty ratio is obtained as in (10) using equation (9).

$$
\frac{V o(s)}{d(s)}=\frac{0.0154 s^{3}+2.778 \times 10^{8} s^{2}-8.889 \times 10^{10} s+5.556 \times 10^{14}}{s^{4}+22.22 s^{3}+9.022 \times 10^{6} s^{2}+1.511 \times 10^{8} s+8.889 \times 10^{11}}
$$

\section{A. Implementation of PI Controller}

The function of the controller is to reduce the steady state error and to regulate the voltage all time irrespective of the load condition and input voltage variation. The magnitude of the output voltage for open loop converter is found to be 99.37 volts with a large overshoot of $90 \%$. To reduce the overshoot at the beginning and to regulate the output voltage PI controller is required. Here the controller parameters are obtained from Zeigler Nichols method. The critical gain and critical time period which are needed for designing controller parameters are obtained from root locus plot. Fig: 7 show the root locus plot of the above transfer function and Fig: 8 show the output voltage of the converter without controller.
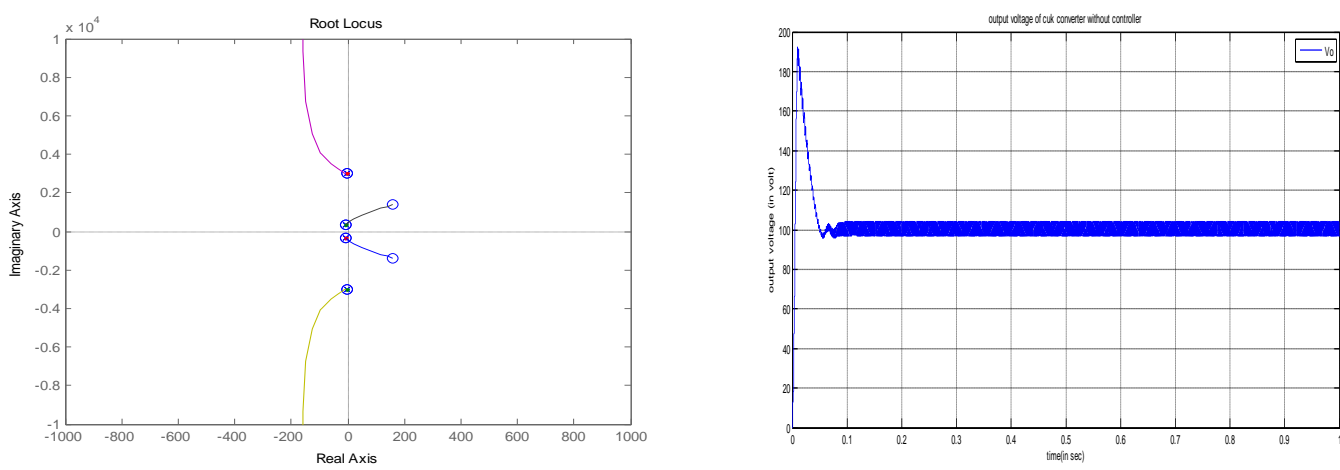

Fig: 7 Root locus plot

Fig: 8 output voltage of the converter without controller

The critical gain and critical time period is calculated from the root locus plot and it is found to be 0.00152 and $0.0145 \mathrm{sec}$ respectively. Using Zeigler Nichols table given in table-1 the $\mathrm{K}_{\mathrm{p}}$ and $\mathrm{K}_{\mathrm{i}}$ values are found to be 0.00076 and 0.10482 respectively.

Table-1

\begin{tabular}{|l|l|l|}
\hline Controller & $\mathrm{Kp}$ & $\mathrm{Ti}$ \\
\hline $\mathrm{PI}$ & $0.5 \mathrm{~K}_{\mathrm{cr}}$ & $0.5 \mathrm{~T}_{\mathrm{cr}}$ \\
\hline
\end{tabular}

The transfer function of the PI controller is obtained as in (11).

$\begin{aligned} G_{c}(s) & =K_{p}+\frac{K_{i}}{s} \\ G_{c}(s) & =\frac{0.00085 s+0.0071}{s}\end{aligned}$ 


\section{Closed Loop Simulation Model}

The closed loop model of PV based CUK converter with MPPT and PI controller is shown in Fig: 9. The MPPT is programmed in MATLAB embedded function and the block is simulated using the Simulink blocks available in the MATLAB library.

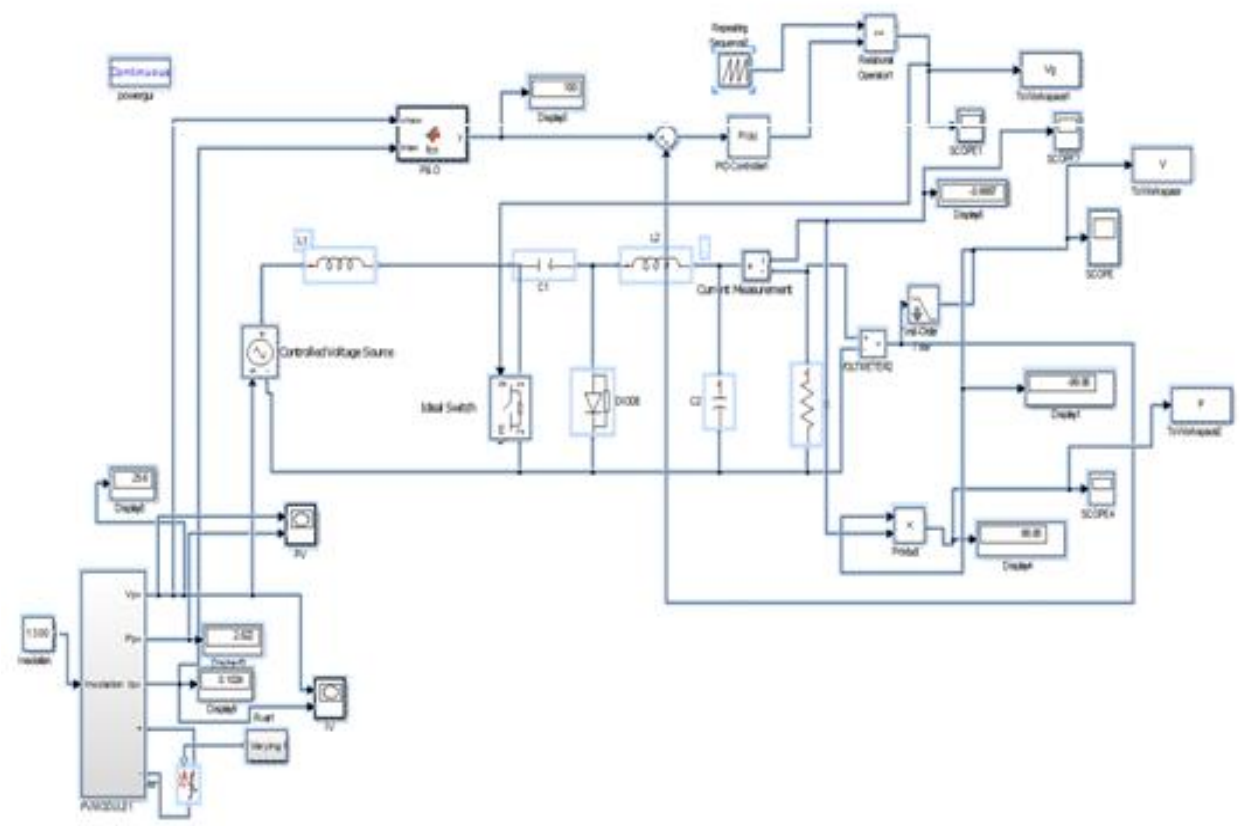

Fig.: 9 closed loop model of PV system with MPPT \& PI controller

\section{Simulation Results}

The proposed model is simulated by varying the irradiance level keeping the temperature constant. Average annual solar radiation arriving at the top of the Earth's surface is roughly $1366 \mathrm{Wp} / \mathrm{m}^{2}$.So here the irradiance value is varied in between the ranges 800 to 1300 watt $/ \mathrm{m}^{2}$.Table- 2 shows the maximum power at different insolation level.

Table-2

\begin{tabular}{|l|l|l|l|l|l|l|}
\hline Irradiance $\left(\mathrm{Wp} / \mathrm{m}^{2}\right)$ & $\mathrm{V}_{\text {out }}($ volt $)$ & $\mathrm{P}_{\text {out }}($ watt $)$ & $\mathrm{V}_{\mathrm{MPP}}($ volt $)$ & $\mathrm{I}_{\mathrm{MPP}}(\mathrm{amp})$ & $\mathrm{P}_{\max }(\mathrm{W})$ & efficiency \\
\hline 800 & -100 & 66.7 & 20 & 3.7 & 68 & $90 \%$ \\
\hline 900 & -100 & 66.7 & 20 & 4.2 & 85 & $79.4 \%$ \\
\hline 1000 & -100 & 66.7 & 20 & 4.7 & 87 & $70.9 \%$ \\
\hline 1100 & -100 & 66.68 & 20 & 5.3 & 96 & $63 \%$ \\
\hline 1200 & -99.98 & 66.67 & 20 & 5.5 & 105 & $60 \%$ \\
\hline 1300 & -99.98 & 66.66 & 20 & 6.1 & 110 & $54.6 \%$ \\
\hline
\end{tabular}

From the table it can be observed that the operating point will change at each time by varying the irradiance level keeping constant $\mathrm{V}_{\text {MPP. }}$. The efficiency will be increased by decreasing the irradiance level. I-V and P-V characteristics for insolation 1000 watt peak $/ \mathrm{m}^{2}$ are shown in fig: 10 . The efficiency can be calculated by using the formula as given in (12).

$$
\eta=\frac{P_{\max }}{V_{M P P} I_{M P P}} \times 100 \ldots \ldots . . .(12)
$$



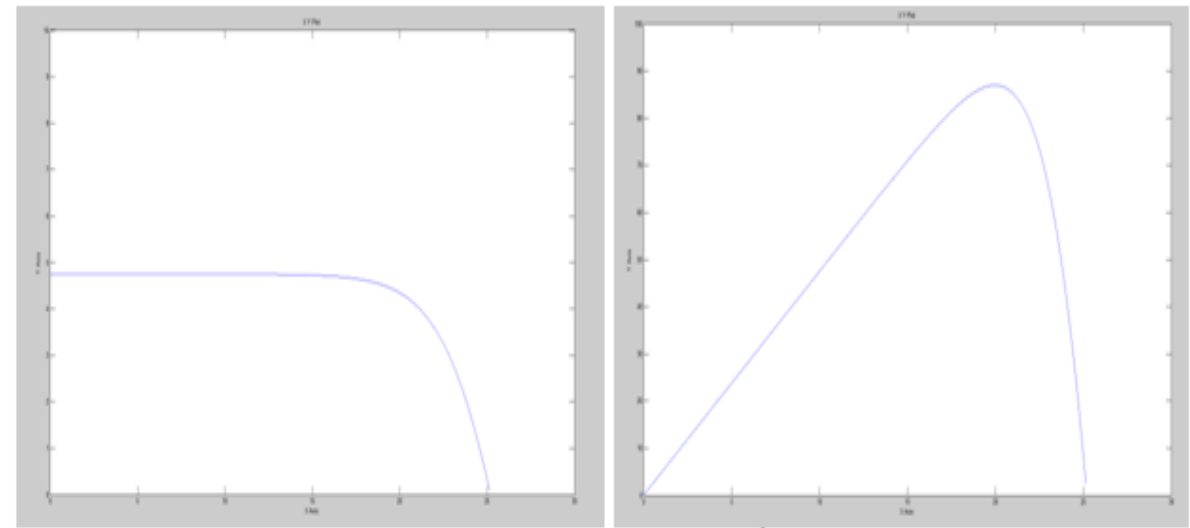

Fig: $10 \mathrm{I} \sim \mathrm{V}$ and $\mathrm{P} \sim \mathrm{V}$ characteristic at $1000 \mathrm{Wp} / \mathrm{m}^{2}$

The output voltage and output power waveform shown in fig: 11 and 12 respectively.

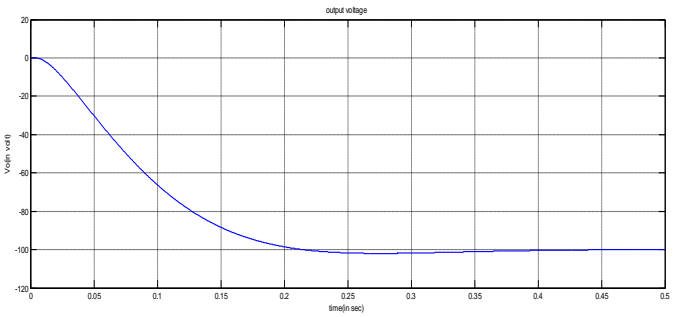

Fig: 11 output voltage waveform of the converter

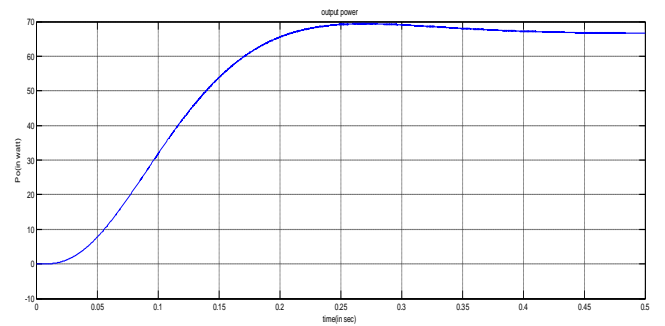

Fig: 12 output power waveform of the converter

The output voltage and output power of the converter remains constant by varying the irradiance. Fig: 13 shows the gate pulse which goes to the switch.

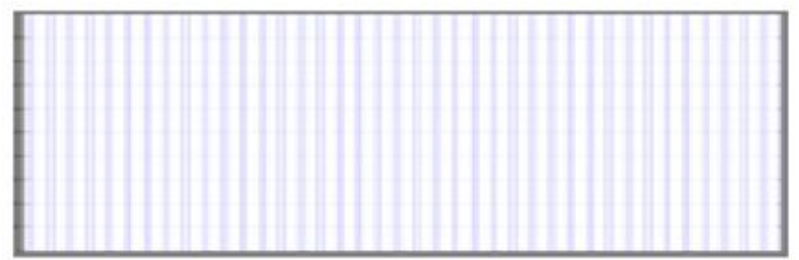

Fig: 13 Gate Pulse to the switch

VII. Conclusion

Here the stand-alone solar-PV generation system with CUK converter has been designed and the performance analysis of the system has been presented using MATLAB/Simulink software with different irradiance. From the steady state analysis it can be observed that the system attains the maximum power point tracking successfully despite of fluctuations in insolation. The system can track the maximum power point very quickly when the environmental condition changes. 


\section{References}

[1]. Tekeshwar Prasad Sahu, T.V. Dixit and Ramesh Kumar," Simulation and Analysis of Perturb and Observe MPPT Algorithm for PV Array Using CंUK Converter" Advance in Electronic and Electric Engineering. ISSN 2231-1297, Volume 4, Number 2 (2014), pp. 213-224.

[2]. Cuauhtemoc Rodriguez, Member, IEEE, and Gehan A. J. Amaratunga, Member, IEEE, " Analytic Solution to the Photovoltaic Maximum Power Point Problem" IEEE TRANSACTIONS ON CIRCUITS AND SYSTEMS—I: REGULAR PAPERS, VOL. 54, NO. 9, SEPTEMBER 2007.

[3]. Dr.L.V.NarasimhaRao Ramesh.Vaddi, "Simulation Cuk Converter Using Incremental Conductance MPPT with Direct Control Method" International Journal of Science, Engineering and Technology Research (IJSETR), Volume 3, Issue 4, April 2014.

[4]. R.B.Wankhede1 PROF.U.B.Vaidya, "Energy Comparison of MPPT Techniques Using Cuk Converter" International Journal of Innovative Research in Advanced Engineering (IJIRAE) ISSN: 2349-2163 Volume 1 Issue 6 (July 2014.

[5]. Diva Catherine, Kavitha Bhaskar, "SIMULATION OF A SOLAR MPPT CHARGER USING CUK CONVERTER FOR STANDALONE APPLICATION" International Journal of Electrical, Electronics and Computer Systems (IJEECS), ISSN (Online): 2347-2820, Volume-1, Issue -1, 2013.

[6]. Srushti R.Chafle, Uttam B. Vaidya, Z.J.Khan, "DESIGN OF CUK CONVERTER WITH MPPT TECHNIQUE" INTERNATIONAL JOURNAL OF INNOVATIVE RESEARCH IN ELECTRICAL, ELECTRONICS, INSTRUMENTATION AND CONTROL ENGINEERING Vol. 1, Issue 4, July 2013.

[7]. RAHUL RAWAT \& S. S. CHANDEL, "HILL CLIMBING TECHNIQUES FOR TRACKING MAXIMUM POWER POINT IN SOLAR PHOTOVOLTAIC SYSTEMS-A REVIEW" Special Issue of International Journal of Sustainable Development and Green Economics (IJSDGE), ISSN No.: 2315-4721, V-2, I-1, 2013.

[8]. D. W. Hart, Introduction to Power Electronics, Prentice-Hall, Englewood Cliffs, NJ, 1997.

[9]. Ned Mohan, T.M.Undeland and W.P. Robbins, Power Electronics: Converter, Applications and Devices, Second Edition, John Wiley and Sons, 1995. 